\title{
Torsional Response and Ductility Demands of Asymmetrical Buildings using Nonlinear Dynamic Analysis
}

\author{
Mr. Md Masihuddin Siddiqui ${ }^{1}$, Mr. Salman Muqeet Ahmed ${ }^{2}$ \\ ${ }^{I}$ (Asst. Professor, C.E.D; Muffakham Jah College of Engineering \& Technology, India) \\ ${ }^{2}$ (Student, M.E Structural Engg. Muffakham Jah College of Engg \& Technology, India)
}

\begin{abstract}
In the seismic design of structures, asymmetrical buildings often sustain more extensive damages as compared to symmetric buildings. Seismic response of an asymmetric building subjected to ground motion tends to be significantly stronger due to torsional effects. These effects arise from the non-uniform distribution of mass, stiffness and strength. Performance of an asymmetric building can be quantified by responses such as rotation of the floor, base torsion, ductility demands etc. The lateral-torsional coupling due to eccentricity between center of mass $(C M)$ and center of rigidity $(C R)$ in asymmetric building structures generates torsional moment which in turn increases the floor rotation as well as base torsion. In the present study, Non-Linear Time History Analysis (NL-THA) of asymmetric buildings with re-entrant corner for five, ten and fifteen stories is carried out. It has been evaluated that it is possible to effectively reduce torsional and rotational effect within an irregular building up to 15 stories by properly configuring the lateral load resisting members.
\end{abstract}

Keywords: Asymmetrical Buidlings, Base Torsion, Ductility Ratio, Nonlinear Time History Analysis.

\section{Introduction}

The behaviour of a buildings during an earthquake depends on several factors; stiffness, adequate lateral strength, ductility, configurations etc. The buildings with regular geometry and uniformly distributed mass and stiffness in plan as well as in elevation suffer much less damage compared to irregular configurations. However, engineers and architects today are expected to be equipped with the skills and knowledge to design more and more asymmetrical buildings as is the trend and the requirements of the modern urban scape. Conventional Seismic codes use the concept of stiffness eccentricity to overcome the issue of torsional moment in asymmetrical buildings. However, there is a relatively poor correlation between structural eccentricity or stiffness eccentricity and the inelastic torsional response of asymmetrical buildings. In elastic range, the traditionally used stiffness eccentricity is useful to estimate the induced torsional moment. Once the structure is excited into inelastic range, the center of resistance no longer remains constant due to yielding, loading and unloading of different resisting elements ${ }^{[1]}$. Therefore, there is a need to study and identify different parameter that captures the inelastic response of the structure.

During earthquake vibrations, asymmetrical structural system's inertia force $\left(\mathrm{f}_{\mathrm{I}}\right)$ acts through the center of mass while the resisting force $\left(f_{R}\right)$ acts through center of rigidity. The coupling of earthquake force $\left(P_{\text {eff }}\right)$ and resistive force $\left(f_{R}\right)$ will cause torsional moment $(T M)$. The building will try to rotate about its center of rigidity. Whereas, in the case of symmetrical building center of mass and center of rigidity will coincide. So, the building will move only in translation manner. Fig 1 shows the generation of torsional moment in building.

$$
\mathrm{TM}=\mathrm{P}_{\text {eff }} * \mathrm{e}
$$

Where, $\mathrm{e}=$ stiffness eccentricity (offset between center of mass and rigidity)

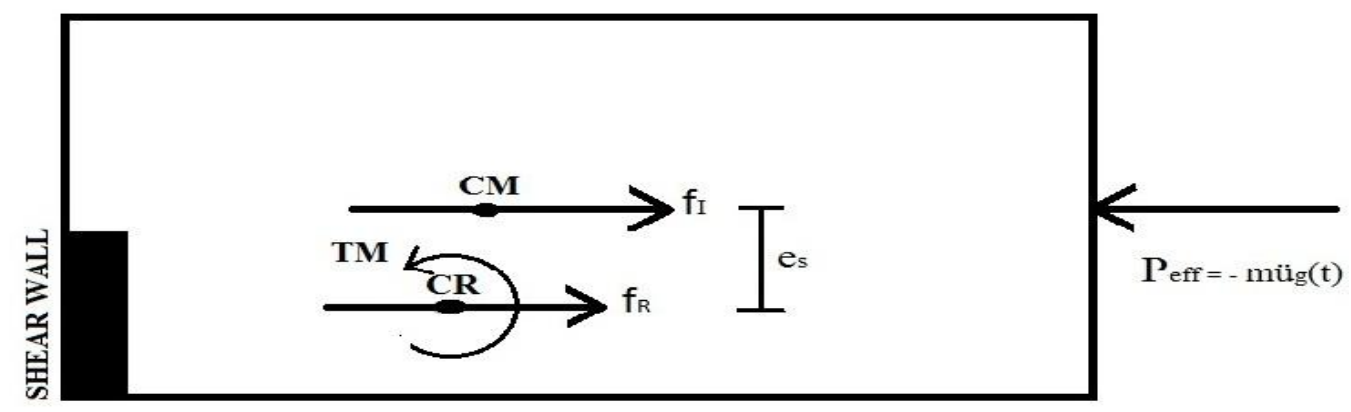

Figure 1: Generation of the Torsional moment 
Center of mass (CM) is the point where entire mass of the system is concentrated. During an earthquake, acceleration induced inertia forces will be developed at each floor level, where the mass of the entire storey may be assumed to be concentrated. The coordinates of center of mass is given by

$\mathrm{X}_{\mathrm{CM}}=\frac{\Sigma \mathrm{Pi} * \mathrm{xi}}{\Sigma \mathrm{Pi}}, \mathrm{Y}_{\mathrm{CM}}=\frac{\Sigma \mathrm{Pi} * \mathrm{yi}}{\Sigma \mathrm{Pi}}$

Center of Rigidity (CR) is the point through which resistive force of the structure acts. It is also referred as center of stiffness of the system. The coordinates of center of stiffness is given by

$$
\mathrm{X}_{\mathrm{CR}}=\frac{\Sigma \mathrm{Kyi} * \mathrm{xi}}{\Sigma \mathrm{Ki}}, \mathrm{Y}_{\mathrm{CR}}=\frac{\Sigma \mathrm{Kxi} * \mathrm{yi}}{\Sigma \mathrm{Ki}}
$$

Center of Strength $(\mathbf{C V})$ is the point where yield strength of the resisting elements acts. The coordinates of the center of strength is given by

$\mathrm{X}_{\mathrm{CV}}=\frac{\Sigma \mathrm{Vyi} * \mathrm{xi}}{\Sigma \mathrm{Vi}}, \mathrm{Y}_{\mathrm{CV}}=\frac{\Sigma \mathrm{Vxi} * \mathrm{yi}}{\Sigma \mathrm{Vi}}$

Where, $\mathrm{P}=$ axial load on column, $\mathrm{K}=$ stiffness of the column, $\mathrm{V}=$ strength of the column.

\section{Methodology}

The purpose of the non-linear time history analysis (NLTHA) is to evaluate the non-linear response of structural system with respect to torsion and rotation and to compare these parameters to available structures with configuration of centers is tested in this work. Time-History analysis is a step-by-step procedure where the loading and the response history are evaluated at successive time increments, $\Delta t-$ steps. During each step the response is evaluated from the initial conditions existing at the beginning of the step (displacements and velocities) and the loading history in the interval. With this method, the non-linear behaviour may be easily considered by changing the structural properties (e.g. stiffness, $k$ ) from one step to the next. Therefore, this method is one of the most effective for the solution of non-linear response, among the many methods available. The NLTHA is perhaps the only procedure which captures the realistic response of the structures when subjected to real earthquake loading. Clearly, these benefits come at the cost of additional analysis effort, associated with incorporating all important elements, modelling their inelastic load-deformation characteristics, and executing incremental inelastic analysis, preferably with a three-dimensional analytical model.

Ductility ratio

Ductility is a measure of an ability of the structure or structural element to deform without any significant reduction in strength. The ratio of ultimate displacement to yield displacement is called ductility ratio $(\mu)$.

$\mu=\frac{\Delta \mathrm{u}}{\Delta \mathrm{y}}$

where,

$\Delta \mathrm{u}=$ the lateral deflection at the end of the post-elastic range and

$\Delta \mathrm{y}=$ the lateral deflection when yield is first reached.

Components and members

The local concrete members that comprise the major structural elements of the building such as columns, beams, slabs, wall panels, boundary members, joints, etc. Concrete frame building: A building with a monolithically cast concrete structural framing system composed of horizontal and vertical elements which support all vertical gravity loads and also provide resistance to all lateral loads through bending of the framing elements. Deformation- Controlled: Refers to components, elements, actions, or systems which can, and are permitted to, exceed their elastic limit in a ductile manner. Force or stress levels for these components are of lesser importance than the amount or extent of deformation beyond the yield point (ductility demand).

\section{Case Study}

The layout of the plan is asymmetric in both directions with re-entrant corner having bay lengths of $5 \mathrm{~m}$ in $\mathrm{X}$ direction and $4 \mathrm{~m}$ in $\mathrm{Y}$ direction. The models considered are reinforced concrete special moment resisting frame with variable column sizes based on stiffness or strength assignments. All these buildings have been analysed by non- linear dynamic analysis [time history analysis]. The typical storey height is $3 \mathrm{~m}$ for all models. The "Bhuj" earthquake data is used as ground motion data for performing non-linear time history analysis. The records are defined for the acceleration points with respect to a time-interval of 0.005 second. The acceleration record has units of $\mathrm{m} / \mathrm{s}^{2}$ and has a total number of 26,706 acceleration data coordinates.

The plan configurations consists of models for five, ten and fifteen storied building

Model 1(M1) - Building is asymmetric in both X \& Y directions, all column sizes are same. (Basic model with column sizes $300 \times 450$ for 5 , 10 stories and $300 \times 600$ for 15 stories).

Model 2 (M2) - Building with stiffness eccentricity zero.

Model 3 (M3) - Building with strength eccentricity zero.

Model 4 (M4) - Building with proper configuration of centres.

Structural and earthquake data for static loads has been show in Table 1.

International Conference on Recent Innovations in Civil \& Mechanical Engineering $58 \mid$ Page

[i- CAM2K16] DOI: 10.9790/1684-16053015765 
Table 1: Structural data

\begin{tabular}{|l|l|l|}
\hline S.No. & Variable & Data \\
\hline 1 & Type of structure & Moment resisting frame \\
\hline 2 & Number of stories & 5,10 and 15 \\
\hline 3 & Bottom \& Typical storey height & $3 \mathrm{~m}$ \\
\hline 4 & Dead load & $15 \mathrm{kN} / \mathrm{m}$ \\
\hline 5 & Live load & $10 \mathrm{kN} / \mathrm{m}$ \\
\hline 6 & Grade of Concrete \& Steel & $\mathrm{M} 30, \mathrm{Fe} 500$ \\
\hline 7 & Size of beams & $300 \times 500 \mathrm{~mm}$ \\
\hline 8 & Specific weight of RCC & $25 \mathrm{kN} / \mathrm{m}^{3}$ \\
\hline 9 & Seismic Zone & $\mathrm{V}$ \\
\hline 10 & Importance factor & 1 \\
\hline 11 & Reduction factor & 5 \\
\hline 12 & Type of soil & Medium \\
\hline
\end{tabular}

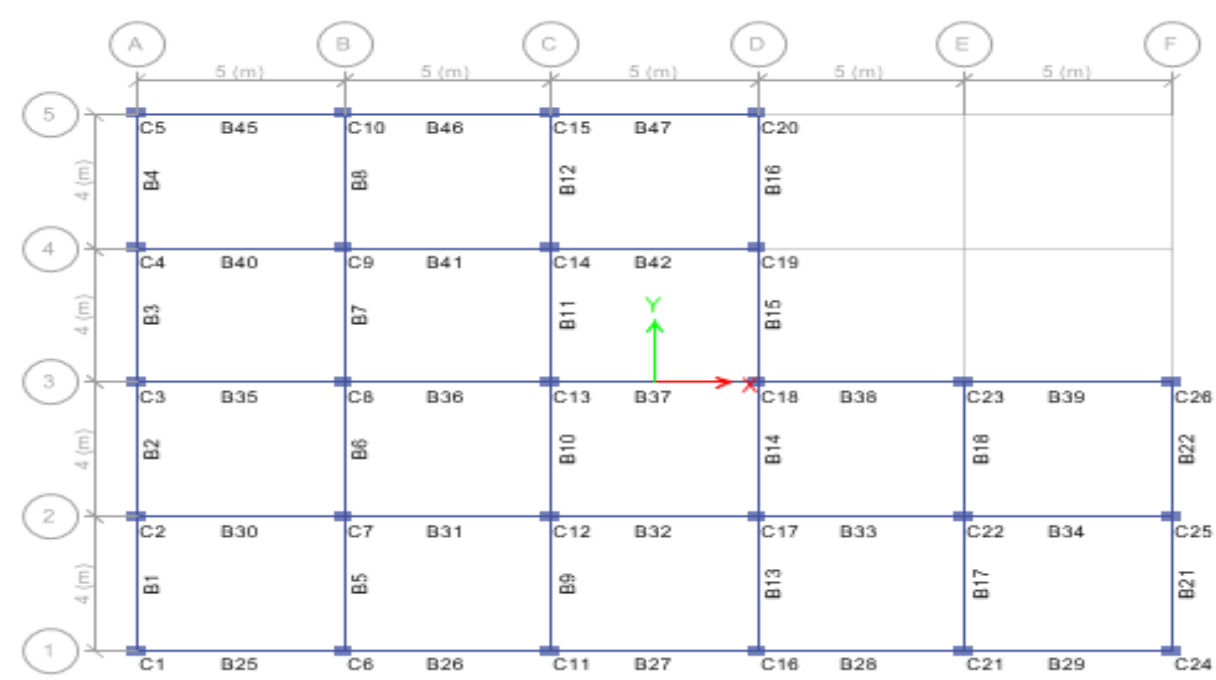

Figure 2: Typical floor Plan of the Building for all the models

Buildings (M1) are modelled in ETABS 2015 with specified column \& beam sizes and dead \& live loads are applied as given in Table1. The structure is designed using equivalent static method as per IS 18932002. The centre of strength and centre of stiffness are calculated to estimate their eccentricities. The building is also subjected to nonlinear time history analysis (NLTHA) for the acceleration data of BHUJ earthquake in both the perpendicular directions i.e., $\mathrm{X}$ direction and $\mathrm{Y}$ direction. The base torsion is recorded for these analyses Using Genetic Algorithms technique, the sizes of lateral load resisting elements (LFRE) of the models M2, M3 and M4 are obtained which refers to buildings with zero stiffness eccentricities (M2), with zero strength eccentricities (M3) and with proper configuration of centres (M4) i.e. centre of strength and centre of stiffness lies on the opposite side of centre of mass \& equidistant from it. Using the new sizes of the LFR elements, the models are again analysed for NLTHA in both X and Y directions.

Table 2 shows the eccentricities for the various models of 5 strorey building.

Table 2: Eccentricities for 5-storey models

\begin{tabular}{|l|l|l|l|l|}
\hline \multirow{2}{*}{ Models } & \multicolumn{2}{|l|}{ Stiffness eccentricity (m) } & \multicolumn{2}{l|}{ Strength eccentricity (m) } \\
\cline { 2 - 5 } & $\mathrm{e}_{\mathrm{sx}}$ & $\mathrm{e}_{\mathrm{sy}}$ & $\mathrm{e}_{\mathrm{vx}}$ & $\mathrm{e}_{\mathrm{vy}}$ \\
\hline M1 & 1.11 & 0.73 & 1.15 & 0.75 \\
\hline M2 & -0.01 & 0.00 & 0.55 & 0.55 \\
\hline M3 & -2.51 & -1.78 & -0.02 & -0.00 \\
\hline M4 & -0.54 & -0.48 & 0.53 & 0.48 \\
\hline
\end{tabular}

\section{Results And Discussion}

The following are the results obtained by carrying out the non-linear time history analysis for different models. Variations in Base Torsion

The following table contains the results of the analysis carried out for the models as discussed earlier. 
Table 3: Base torsion for non-linear dynamic analysis of five storey buildings

\begin{tabular}{|l|l|l|}
\hline Models (5-storey) & $\begin{array}{l}\text { Torsion }(\mathbf{k N m}) \\
\text { NLTH-X }\end{array}$ & $\begin{array}{l}\text { Torsion }(\mathbf{k N m}) \\
\text { NLTH-Y }\end{array}$ \\
\hline M-1 (BM) & 8362 & 8363 \\
\hline M-2 (CS =0) & 4257 & 3906 \\
\hline M-3 (CV =0) & 3255 & 6475 \\
\hline M-4 (CV-CM-CR) & 2773 & 1813 \\
\hline
\end{tabular}

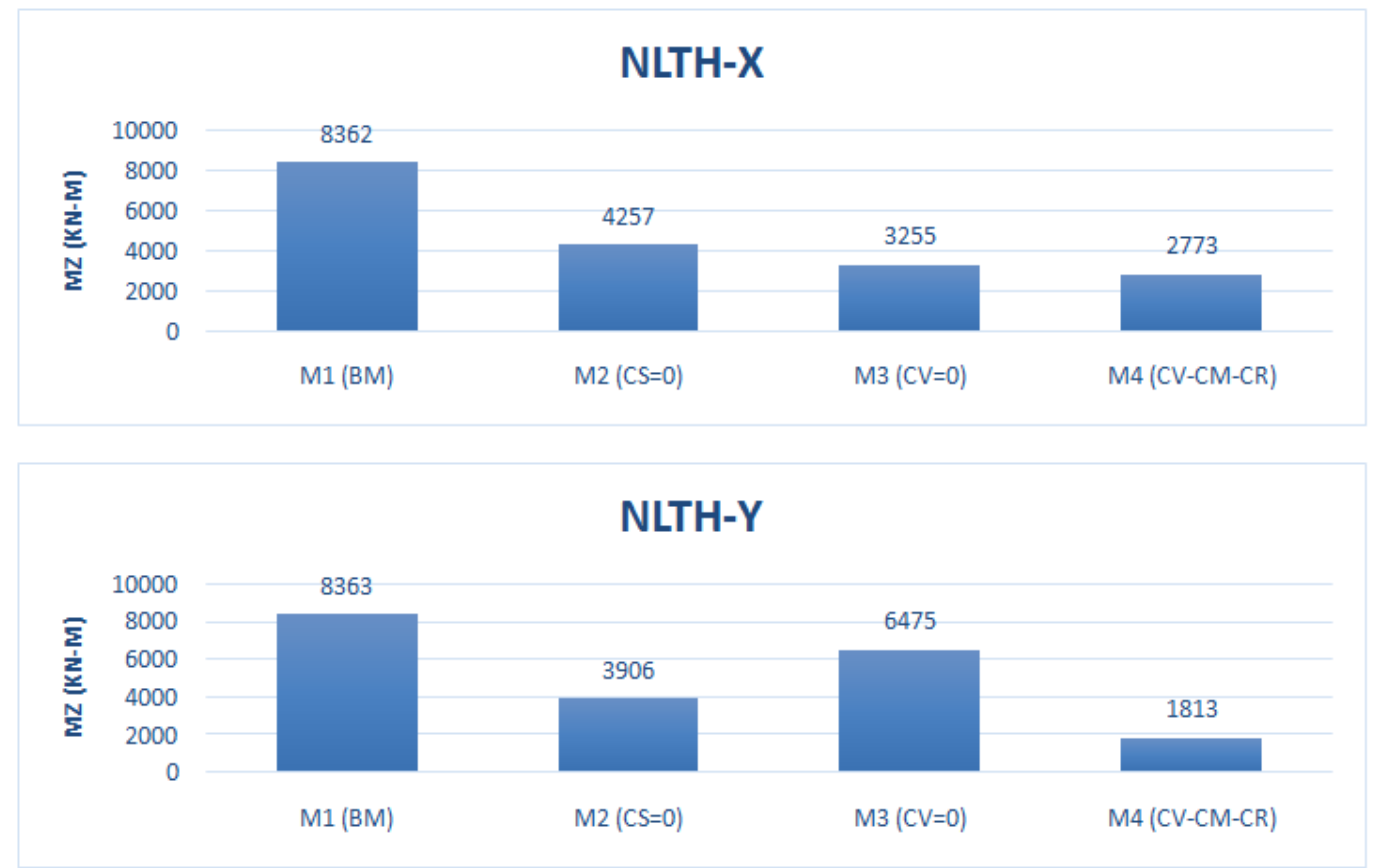

Figure 3: Variation of base torsion for five storey buildings in $\mathrm{X}$ and $\mathrm{Y}$-directions.

While performing Non-Linear Time History Analysis in X-direction for the above models, It was observed that, the variation of maximum base torsion for 5-storey Building was decreased by $49 \%, 23 \%$ and $67 \%$ in $M-2\left(e_{s}=0\right), M-3\left(e_{v}=0\right)$ and $M-4\left(e_{v}=-e_{s}\right)$ when compared with basic model (i.e. $\left.M-1\right)$.

Similarly Performing Non-Linear Time History Analysis in Y-direction shows the variation of maximum base torsion (MZ) for 5-storey Buildings was decreased by 53\%, 23\% and 78\% in M-2, M-3 and M-4 when compared with basic model (i.e. M-1).

Table 4: Base torsion for non-linear dynamic analysis of ten storey buildings

\begin{tabular}{|l|l|l|}
\hline Models (10-storey) & $\begin{array}{l}\text { Torsion }(\mathbf{k N m}) \\
\text { NLTH-X }\end{array}$ & $\begin{array}{l}\text { Torsion }(\mathbf{k N m}) \\
\text { NLTH-Y }\end{array}$ \\
\hline M-1 (BM) & 7749 & 6868 \\
\hline M-2 (CS=0) & 2808 & 3614 \\
\hline M-3 (CV $=0)$ & 1849 & 2269 \\
\hline M-4 (CV-CM-CR) & 3383 & 3073 \\
\hline
\end{tabular}

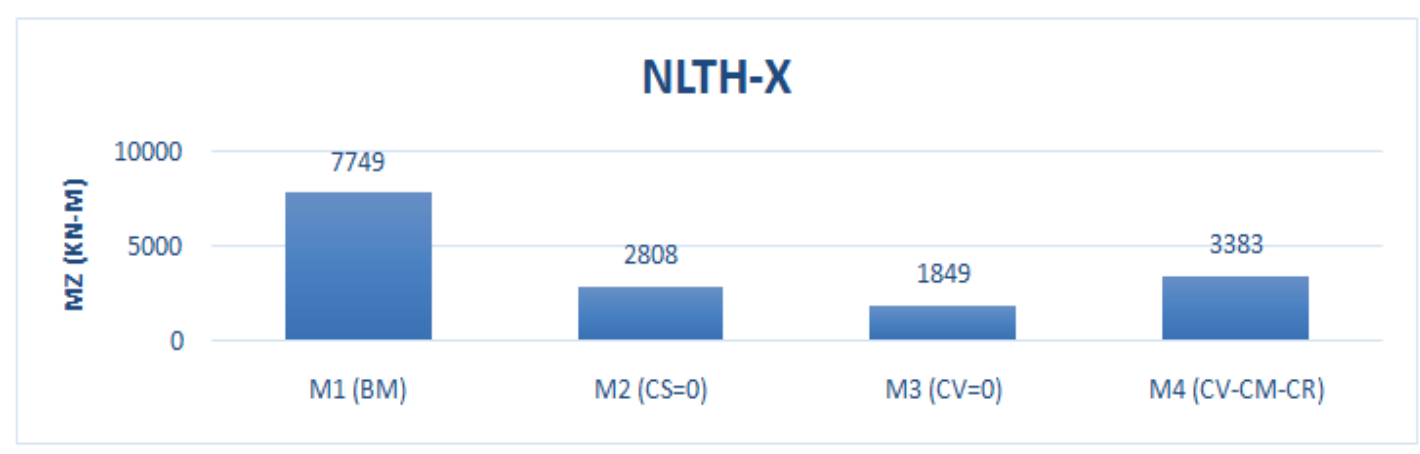




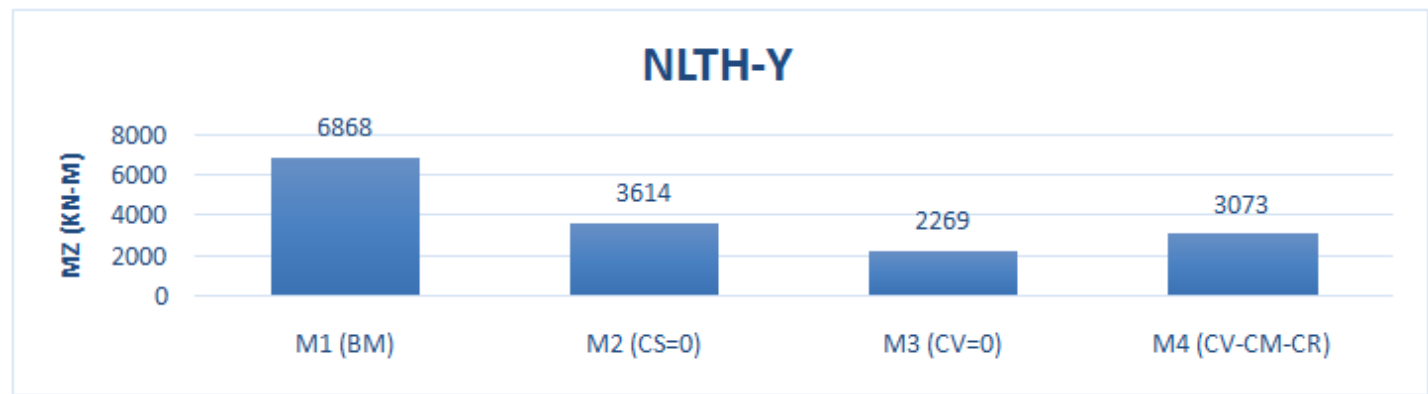

Figure 4: Variation of base torsion for ten storey buildings in X and Y-directions.

The base torsion Buildings was decreased by $64 \%, 76 \%$ and $56 \%$ in $\mathrm{M}-2(\mathrm{es}=0), \mathrm{M}-3(\mathrm{ev}=0)$ and $\mathrm{M}-4(\mathrm{ev}=-\mathrm{es})$ when compared with basic model (i.e. M-1) in X-direction.

Similarly in Y-direction, base torsion was decreased by $47 \%, 67 \%$ and $55 \%$ in $\mathrm{M}-2$, M-3 and M-4 when compared with basic model (i.e. M-1).

Table 5: Base torsion for non-linear dynamic analysis of fifteen storey buildings

\begin{tabular}{|l|l|l|}
\hline Models (15-storey) & $\begin{array}{l}\text { Torsion }(\mathbf{k N m}) \\
\text { NLTH-X }\end{array}$ & $\begin{array}{l}\text { Torsion }(\mathbf{k N m}) \\
\text { NLTH-Y }\end{array}$ \\
\hline M-1 (BM) & 11080 & 9164 \\
\hline M-2 (CS =0) & 3613 & 5891 \\
\hline M-3 (CV =0) & 3512 & 4797 \\
\hline M-4 (CV-CM-CR) & 2374 & 4474 \\
\hline
\end{tabular}

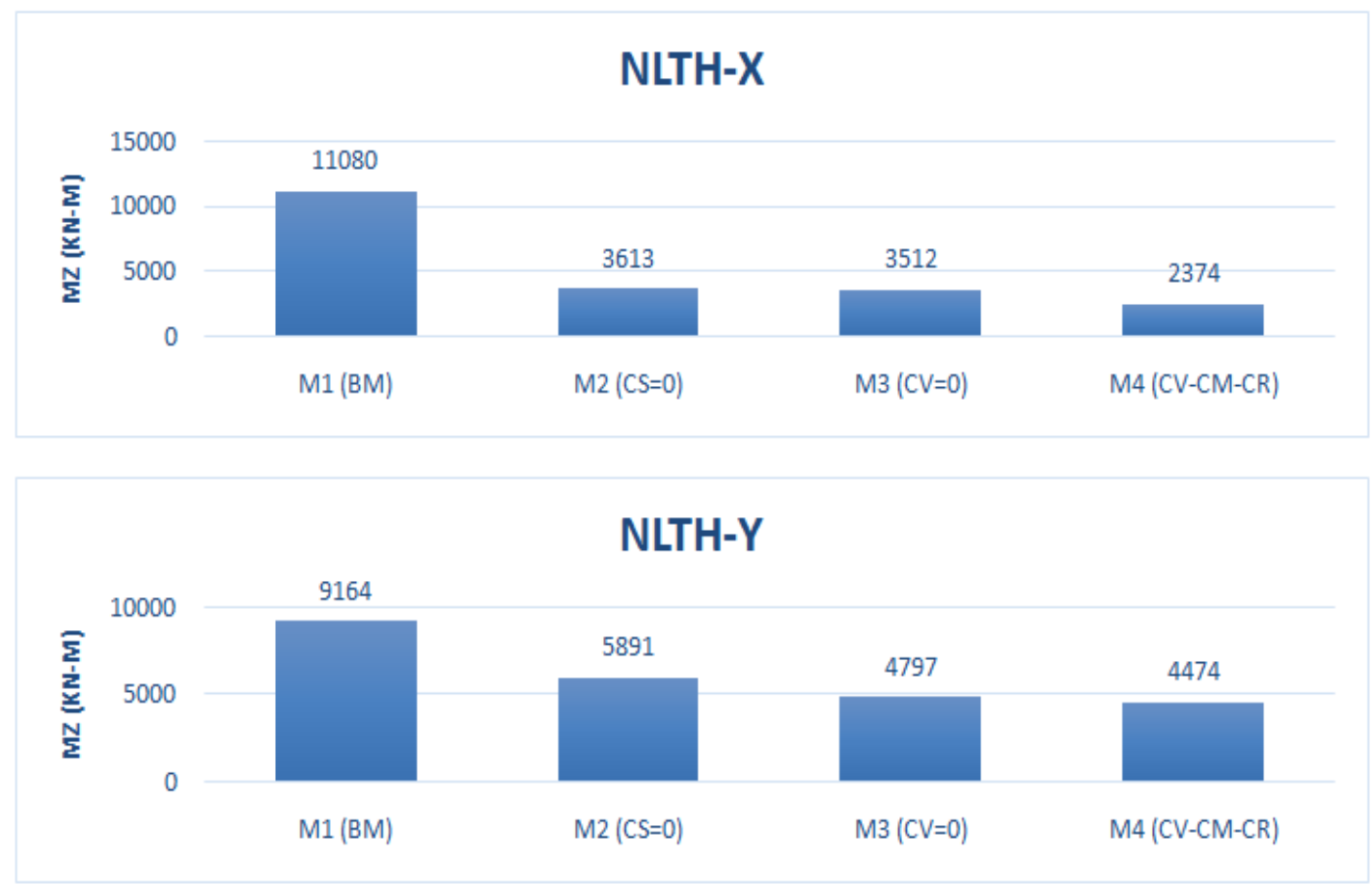

Figure 5: Variation of base torsion for fifteen storey buildings in $\mathrm{X}$ and $\mathrm{Y}$-directions.

The variation of maximum base torsion (MZ) for 15-storey Building was decreased by $67 \%, 68 \%$ and $79 \%$ in M-2(es=0), M-3(ev=0) and M-4(ev=-es) when compared with basic model (i.e. M-1) in X-direction. Similarly in Y-direction, maximum base torsion (MZ) for 15-storey Buildings was decreased by $36 \%, 48 \%$ and $51 \%$ in $\mathrm{M}-2$, M-3 and M-4 when compared with basic model (i.e. M-1).

Ductility Ratio

The following figures contain the results of the analysis carried out for the models as discussed earlier. Ductility ratios of five, ten and fifteen storey buildings performing non-linear static analysis (Push over analysis). Different Soil classes are: A - Hard Rock, B - Rock, C - Very dense soil and soft rock and D - Stiff soil. 
Ductility ratios of 5-storey (using Fe 500 grade steel)

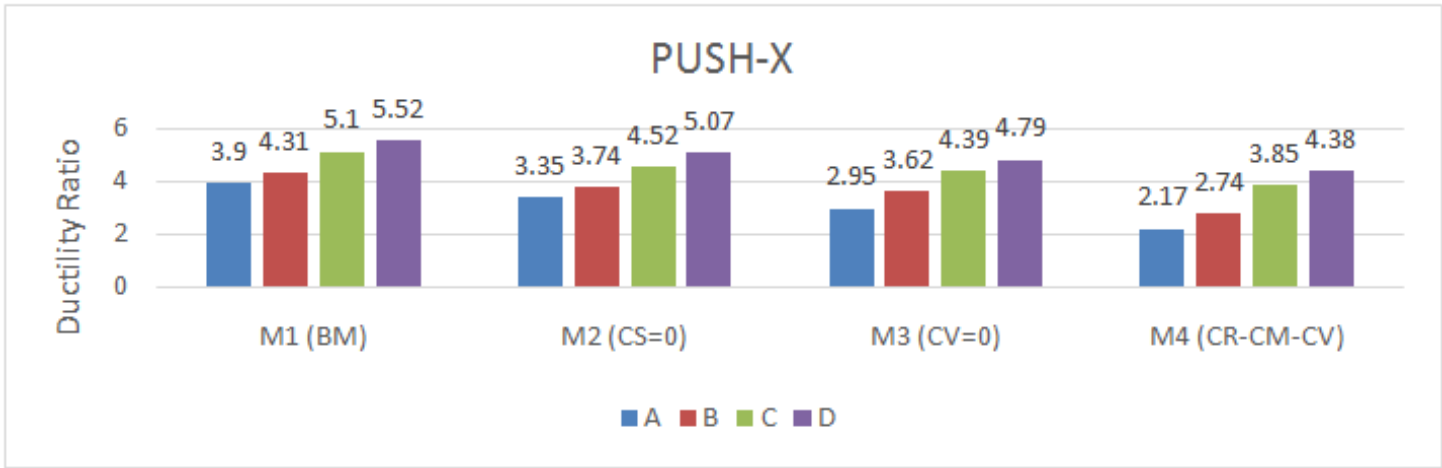

Figure 9 Ductility Ratio (Fe 500) of five storey models w.r.t soil classes in X-direction

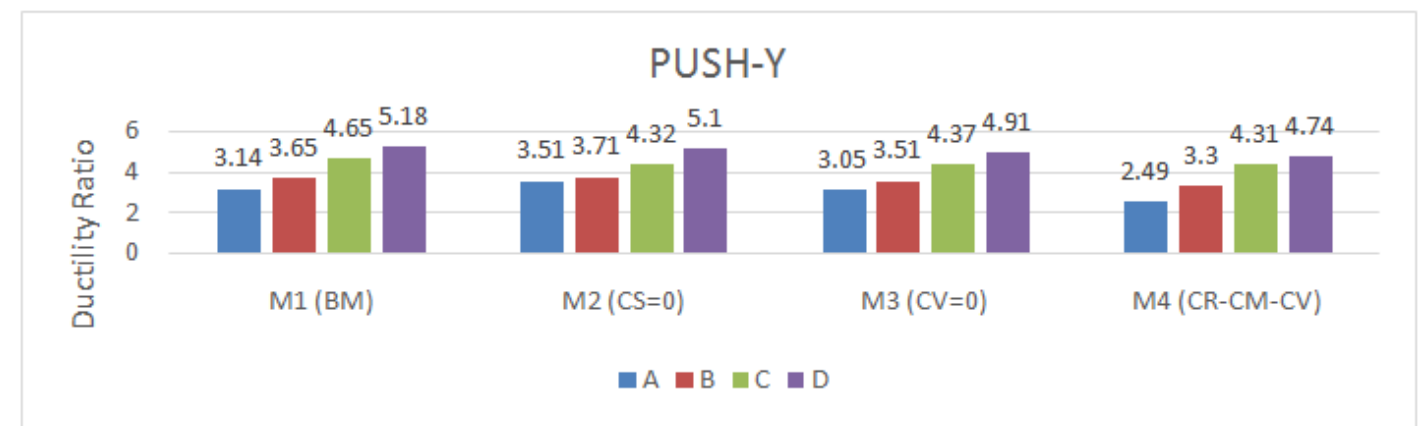

Figure 10 Ductility Ratio (Fe 500) of five storey models w.r.t soil classes in Y-direction

In 5- storey models when performing push over analysis in both $\mathrm{X}$ and $\mathrm{Y}$ directions using Fe 500 grade steel, it was observed that the ductility ratio increases with respect to soil class A(Hard rock), B(Rock), C(Very dense soil and soft rock) and $\mathrm{D}$ (Stiff soil); in increasing order for all models tested.

Ductility ratio of 10-storey (using Fe 500 grade steel)

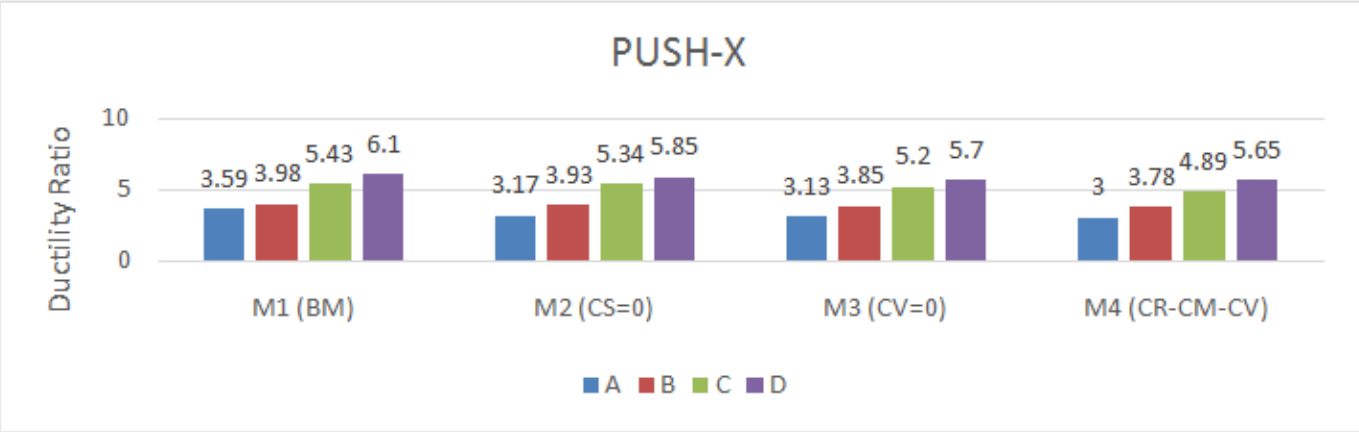

Figure 11 Ductility Ratio (Fe 500) of ten storey models w.r.t soil classes in X-direction

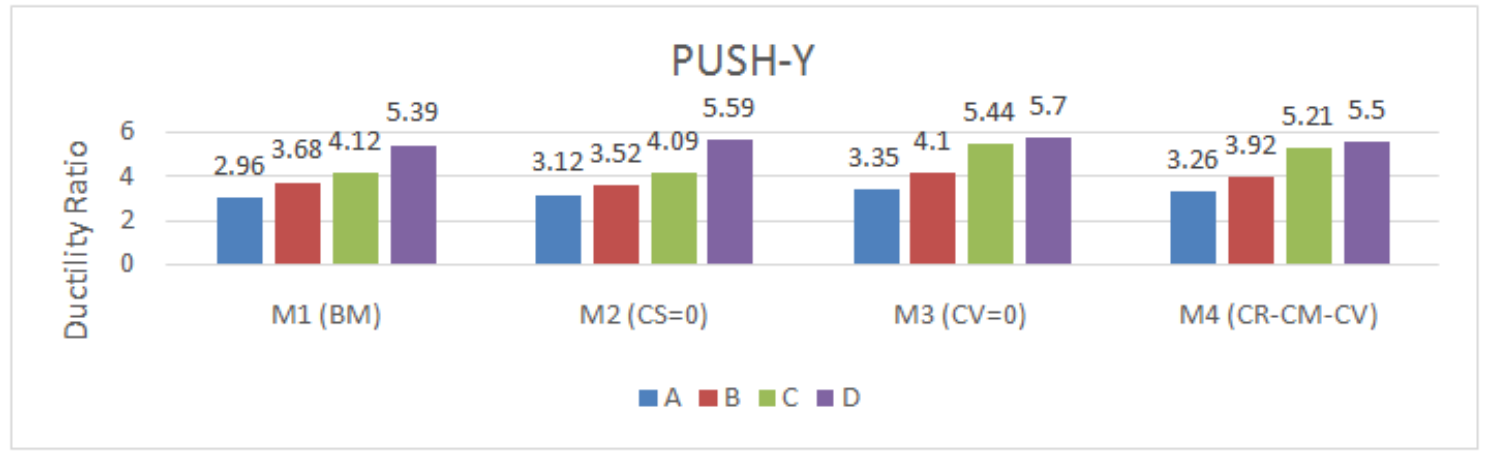

Figure 12 Ductility Ratio (Fe 500) of ten storey models w.r.t soil classes in Y-direction 
In 10- storey models when performing push over analysis in both $\mathrm{X}$ and $\mathrm{Y}$ directions using Fe 500 grade steel, it was observed that the ductility ratio increases with respect to soil class A(Hard rock), B(Rock), C(Very dense soil and soft rock) and D(Stiff soil); in increasing order for all models tested.

Ductility ratio of 15-storey (using Fe 500 grade steel)

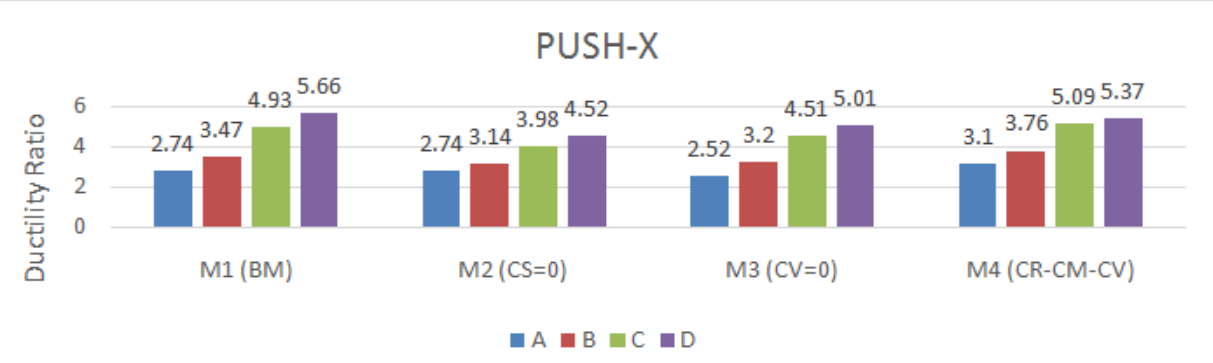

Figure13 Ductility Ratio (Fe 500) of fifteen storey models w.r.t soil classes in X-direction

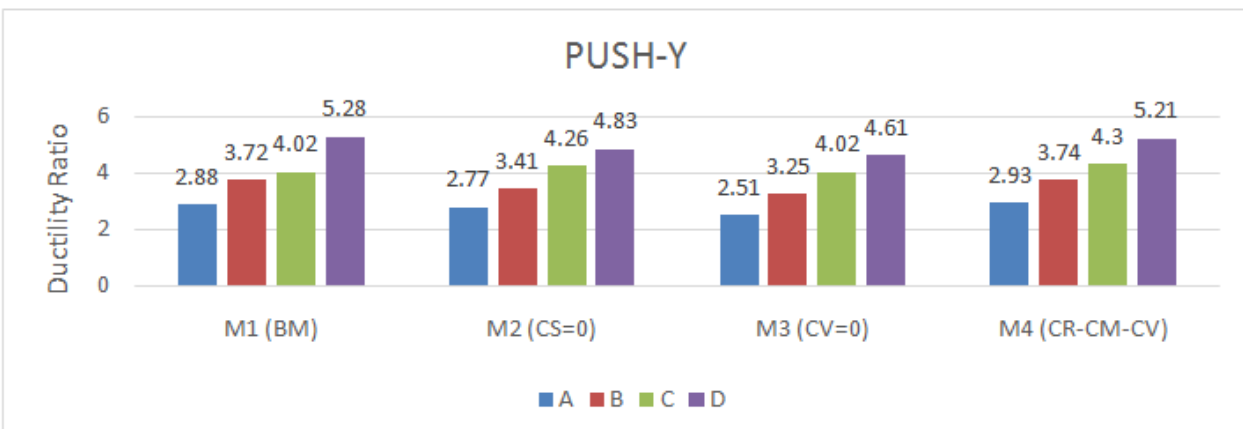

Figure 14 Ductility Ratio (Fe 500) of fifteen storey models w.r.t soil classes in Y-direction

In 15 - storey models when performing push over analysis in both $\mathrm{X}$ and $\mathrm{Y}$ directions using Fe 500 grade steel, it was observed that the ductility ratio increases with respect to soil class A(Hard rock), B(Rock), C(Very dense soil and soft rock) and $\mathrm{D}$ (Stiff soil); in increasing order for all models tested.

\section{Ductility ratio of 5-storey (using Fe 415 grade steel)}

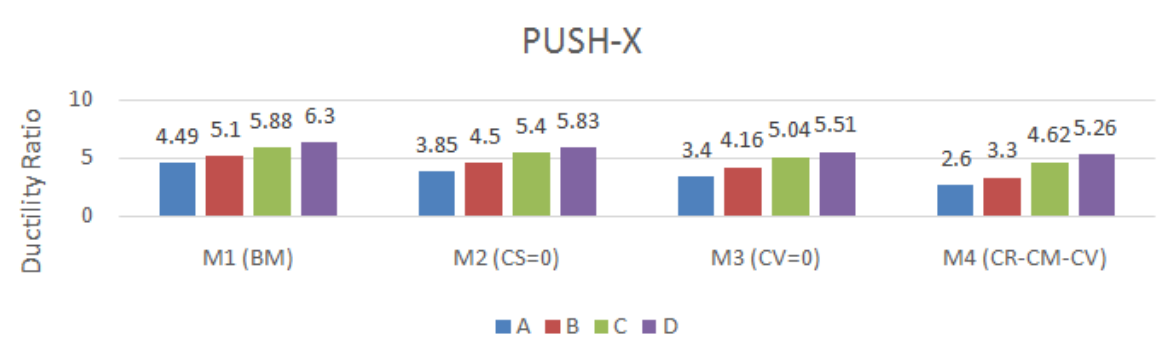

Figure 15 Ductility Ratio D.R (Fe 415) of five storey models w.r.t soil classes in X-direction

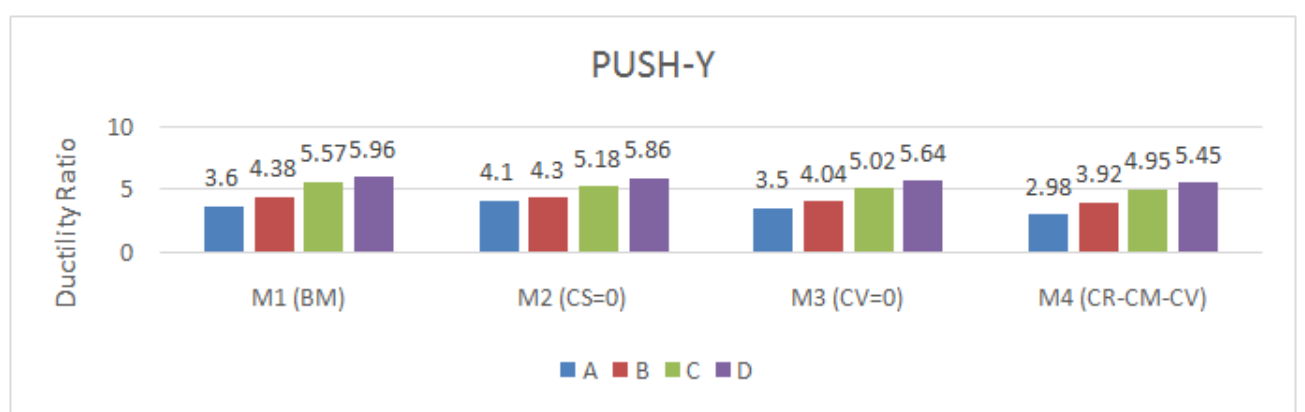

Figure 16 Ductility Ratio (Fe 415) of five storey models w.r.t soil classes in Y-direction 
In 5-storey models when performing push over analysis in both $\mathrm{X}$ and $\mathrm{Y}$ directions using $\mathrm{Fe} 415$ grade steel, it was observed that the ductility ratio increases with respect to soil class A(Hard rock), B(Rock), C(Very dense soil and soft rock) and D(Stiff soil); in increasing order for all models tested.

Ductility ratio of 10-storey (using Fe 415 grade steel)

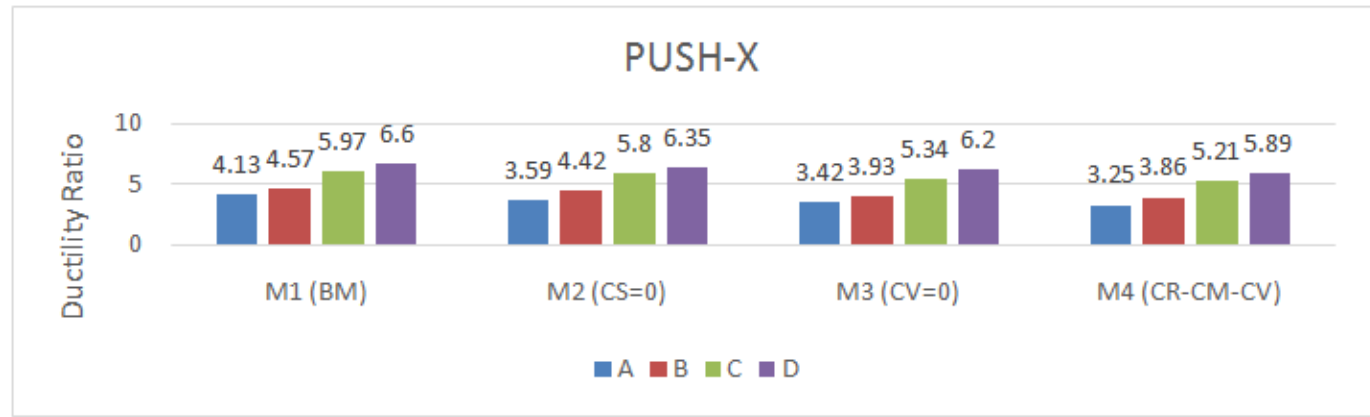

Figure 17 Ductility Ratio (Fe 415) of ten storey models w.r.t soil classes in X-direction

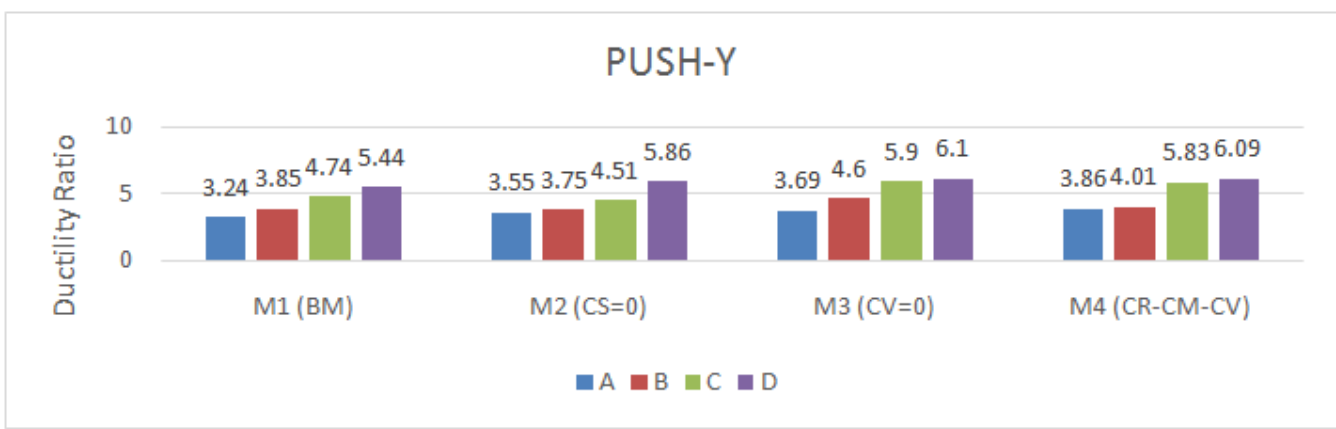

Figure 18 Ductility Ratio (Fe 415) of ten storey models w.r.t soil classes in Y-direction

In 10-storey models when performing push over analysis in both $\mathrm{X}$ and $\mathrm{Y}$ directions using Fe 415 grade steel, it was observed that the ductility ratio increases with respect to soil class $\mathrm{A}$ (Hard rock), B(Rock), C(Very dense soil and soft rock) and D(Stiff soil); in increasing order for all models tested.

\section{Ductility ratio of 15-storey (using Fe 415 grade steel)}

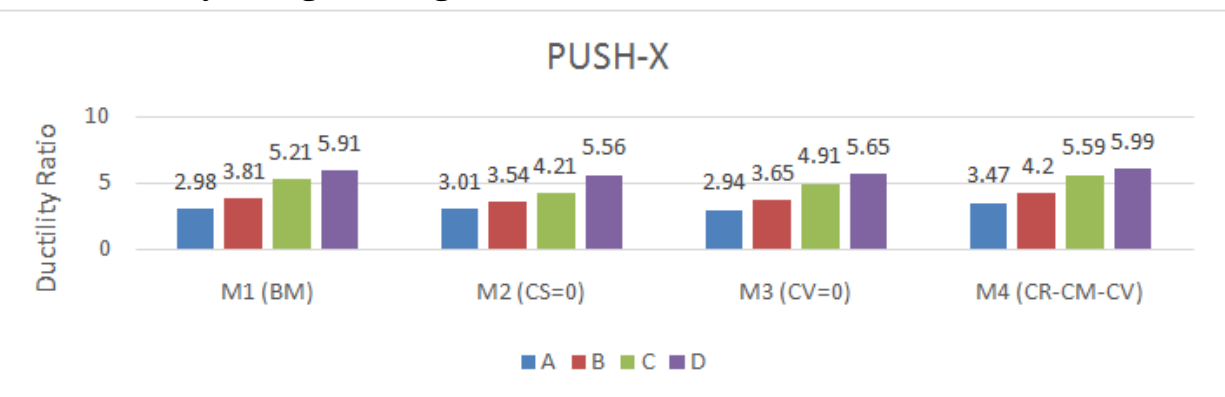

Figure 19 Ductility Ratio (Fe 415) of fifteen storey models w.r.t soil classes in X-direction

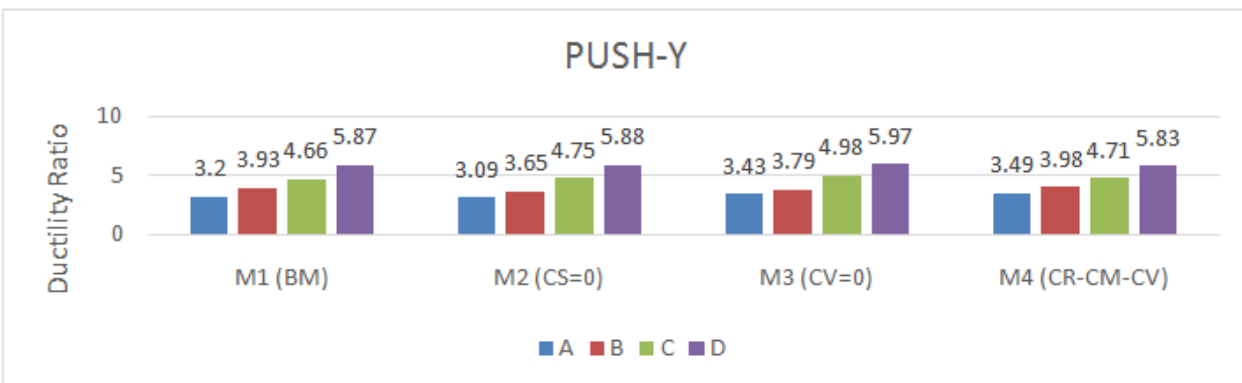

Figure 20 Ductility Ratio (Fe 415) for fifteen storey models w.r.t soil classes in Y-direction 
In 15-storey models when performing push over analysis in both $\mathrm{X}$ and $\mathrm{Y}$ directions using $\mathrm{Fe} 415$ grade steel, it was observed that the ductility ratio increases with respect to soil class $\mathrm{A}($ Hard rock), B(Rock), $\mathrm{C}$ (Very dense soil and soft rock) and D(Stiff soil); in increasing order for all models tested.

\section{Conclusions}

The following are the conclusions drawn from the present work:

1. In basic model the eccentricity will not change if the no. of stories are increasing from five to fifteen storey, as it depends on the plan of the building.

2. In the models that differ from Basic model (M-1) in column size only i.e. es=0 (M-2), ev=0 (M-3) and ev=es (M-4), there was notable reduction in base torsion when non-linear time history analysis was done on five, ten and fifteen storey variants. In model 4 the desired reduction owes itself to the fact that CV and CR to be located on opposite sides of CM.

3. The assignment of strength to LFRE will affect both the strength and stiffness distributions, we advocate a strength assignment that satisfies the balanced CV-CR and CM location criterion. This criterion requires that $\mathrm{CV}$ and CR be located on opposite sides of CM.

4. Performing Push over analysis for $M-1, M-2, M-3$ and $M-4$ shows that the ductility ratio increases with respect to site class $\mathrm{A}$ (Hard rock), B(Rock), C(Very dense soil and soft rock) and D(Stiff soil); in increasing order for all models tested.

5. Performing Push over analysis also shows that the yield strength of steel and ductility are inversely proportional.

\section{References}

[1] A.W. Sadek and W.K. Tso, (Strength eccentricity concept for inelastic analysis of asymmetric structures).

[2] Sachin G.Maske and Dr. P.S. Pajgade 2013, (Torsional Behaviour of Asymmetrical Buildings).

[3] Mr. Sandesh N. Suryawanshi, Prof. S. B. Kadam, Dr. S. N. Tande 2014, (Torsional Behaviour of Asymmetrical Buildings in Plan under Seismic Forces).

[4] Amin Alavi and Prof. P.SrinivasaRao 2013, (Influence of Torsional Irregularities of RC Buildings in High Seismic Zone).

[5] Prof. Wakchaure M. R, Nagare Y .U 2013, (Effects of Torsion Consideration in Analysis of Multi Storey Frame).

[6] Rucha S. Banginwar, M. R. Vyawahare, P.O. Modani 2012, (Effect of plans Configurations on the Seismic Behaviour of the Structure by Response Spectrum Method).

[7] Dr. Sudhir K jain in "Explanatory Examples on Indian Seismic Code IS 1893 (Part 1).

[8] Vipin Gupta and Dr. P.S. Pajgade 2015, (Torsional Behavior of Multistorey Buildings with Different Structural Irregularities).

[9] A.Aziminejad , A.S. Moghadam and W.K. Tso 2008, “A New Methodology for Designing Multi-storey Asymmetrical Buildings"

[10] Mohammad Parsaei Maram, Dr. K Rama Mohana Rao 2013, "Effect Of Location of Lateral Force Resisting System On Seismic Behaviour Of RC Building” 